\title{
Atrial Fibrillation With Valvular Heart Disease \\ - New Insight Into Clinical Outcomes -
}

\author{
Sayaka Kurokawa, MD; Yasuo Okumura, MD
}

$\mathbf{W}$ hile the number of patients with atrial fibrillation (AF) has been dramatically increasing in the super-aged society of Japan, the causes of AF are changing. Mitral stenosis (MS), the primary manifestation of rheumatic heart disease, is now a relatively uncommon cause, and it has recently been documented in only $3.5 \%$ of the J-RHYTHM Registry ${ }^{1}$ patients. The annual incidence of stroke/systemic embolism (SE) is thought to be 3.7\% in patients with MS. Concomitant MS and AF increases the stroke/SE risk by 3- to 7-fold that of MS alone. ${ }^{2}$ In contrast, the 30-year survival rate of patients with mechanical valve replacements in Japan is relatively high at $38 \%$, while AF is the only independent predictor of stroke/SE. ${ }^{3}$ Stroke/SEs

\section{Article p 714}

are considered to occur frequently in patients with MS or mechanical valves, as defined by the "valvular AF (VAF)", for which warfarin should be administered according to the AF management guidelines in $\mathrm{Japan}^{4}$ and Western countries. ${ }^{5}$ However, warfarin or non-vitamin $\mathrm{K}$ antagonist oral anticoagulants (NOACs) can be used for aortic stenosis (AS), aortic regurgitation, mitral regurgitation, and tricuspid regurgitation, so called "non-valvular AF with valvular heart disease (NVAF-VHD)". Nonetheless, there are few data on the current status of oral anticoagulants (OACs)

\begin{tabular}{|c|c|c|c|}
\hline Authors & Doi et al6 & Thomas et $\mathrm{al}^{7}$ & Bisson et $\mathbf{a l}^{8}$ \\
\hline $\begin{array}{l}\text { Journal, } \\
\text { year published }\end{array}$ & Circ J, 2020 & J Am Heart Assoc, 2017 & Int J Cardiol, 2018 \\
\hline Country & Japan & USA & France \\
\hline Study type & Prospective registry & Prospective registry & Retrospective database \\
\hline Study name & Fushimi AF registry & ORBIT-AF & $\mathrm{CHRU}$ \\
\hline $\begin{array}{l}\text { Number of study } \\
\text { patients }\end{array}$ & 3,566 & 9,748 & 8,962 \\
\hline Follow-up time & $\begin{array}{l}\text { Enrollment: March } 2011 \text { to } \\
\text { November } 2017 \\
\text { Follow up: until November } 2018\end{array}$ & Median $2.5($ IQR, 1.8-3.0) years & $\begin{array}{l}\text { Mean } 1,264 \pm 1,160 \text { days } \\
\text { Median } 922(\text { IQR, } 234-2,083) \text { days }\end{array}$ \\
\hline Group (n) & $\begin{array}{l}\text { (1) VAF: mild-severe MS or } \\
\text { prosthetic heart valve (131) } \\
\text { (2) NVAF-VHD: mild-severe AS, AR, } \\
\text { MR, or TR }(583) \\
\text { (3) No-VHD }(2,852)\end{array}$ & $\begin{array}{l}\text { (1) Moderate-severe MS or MV } \\
\text { (403) } \\
\text { (2) Moderate-severe AS, AR, MR, } \\
\text { or TR }(1,847) \\
\text { (3) No or mild VHD }(7,043) \\
\text { (4) BPV, surgical repair, or } \\
\text { balloon valvuloplasty (455) }\end{array}$ & $\begin{array}{l}\text { (1) Rheumatic severe MS or mechanical } \\
\text { prosthetic heart valves (357) } \\
\text { (2) Severe AS, AR, MR or valve } \\
\text { bioprosthesis or repair }(1,754) \\
\text { (3) No-VHD }(6,851)\end{array}$ \\
\hline Average age (years) & $\begin{array}{l}\text { (1) } 74.3 \pm 8.9 \\
\text { (2) } 76.9 \pm 10.5 \\
\text { (3) } 72.9 \pm 10.7\end{array}$ & $\begin{array}{l}\text { (1) } 74(65-81) \\
\text { (2) } 79(72-85) \\
\text { (3) } 73(65-81) \\
\text { (4) } 78(70-83)\end{array}$ & $\begin{array}{l}\text { (1) } 68 \pm 13 \\
\text { (2) } 75 \pm 11 \\
\text { (3) } 70 \pm 15\end{array}$ \\
\hline $\begin{array}{l}\mathrm{CHA}_{2} \mathrm{DS}_{2}-\mathrm{VASc} \\
\text { score }\end{array}$ & $\begin{array}{l}\text { (1) } 3.7 \pm 1.3 \\
\text { (2) } 4.0 \pm 1.6 \\
\text { (3) } 3.3 \pm 1.7\end{array}$ & $\begin{array}{l}\text { (1) } 4(3-5) \\
\text { (2) } 4(4-6) \\
\text { (3) } 4(3-5) \\
\text { (4) } 5(4-6)\end{array}$ & $\begin{array}{l}\text { (1) } 3 \pm 1.7 \\
\text { (2) } 3.6 \pm 1.6 \\
\text { (3) } 2.9 \pm 1.8\end{array}$ \\
\hline
\end{tabular}

(Table continued the next page.)

The opinions expressed in this article are not necessarily those of the editors or of the Japanese Circulation Society.

Received March 16, 2020; accepted March 18, 2020; J-STAGE Advance Publication released online April 3, 2020

Division of Cardiology, Department of Medicine, Nihon University School of Medicine, Tokyo, Japan

Mailing address: Yasuo Okumura, MD, Division of Cardiology, Department of Medicine, Nihon University School of Medicine, 30-1 Ohyaguchi-kamicho, Itabashi-ku, Tokyo 173-8610, Japan. E-mail: okumura.yasuo@nihon-u.ac.jp

ISSN-1346-9843 All rights are reserved to the Japanese Circulation Society. For permissions, please e-mail: cj@j-circ.or.jp 


\begin{tabular}{|c|c|c|c|}
\hline \begin{tabular}{l}
\multicolumn{1}{c}{ Authors } \\
Oral anticoagulant \\
rates $(\%)$
\end{tabular} & Doi et $\mathbf{a l}^{6}$ & Thomas et $\mathrm{al}^{7}$ & Bisson et $a^{8}$ \\
\hline Warfarin & $\begin{array}{l}\text { (1) } 77.9 \\
\text { (2) } 53.2 \\
\text { (3) } 38.7\end{array}$ & $\begin{array}{l}\text { (1) } 96.3 \\
\text { (2) } 76.5 \\
\text { (3) } 68.4 \\
\text { (4) } 80.7\end{array}$ & $\begin{array}{l}\text { (1) } 78 \\
\text { (2) } 61 \\
\text { (3) } 55\end{array}$ \\
\hline NOAC & $\begin{array}{l}\text { (1) } 0.7 \\
\text { (2) } 9.8 \\
\text { (3) } 16.9\end{array}$ & $\begin{array}{l}\text { (1) } 1.5 \\
\text { (2) } 3.8 \\
\text { (3) } 5.6 \\
\text { (4) } 2.2\end{array}$ & $\begin{array}{l}\text { (1) } 0 \\
\text { (2) } 0 \\
\text { (3) } 0\end{array}$ \\
\hline Stroke/SE & & $\mathrm{P}=0.949^{*}$ & \\
\hline $\begin{array}{l}\text { Adjusted HR } \\
(95 \% \mathrm{Cl}), \mathrm{P} \text { value }\end{array}$ & $\begin{array}{l}\text { (1) } 0.98(0.54-1.78), P=0.95 \\
\text { (2) } 1.05(0.77-1.43), P=0.75 \\
\text { (3) reference }\end{array}$ & $\begin{array}{l}\text { (1) } 0.93(0.58-1.49) \\
\text { (2) } 0.97(0.74-1.27) \\
\text { (3) reference } \\
\text { (4) } 1.07(0.73-1.57)\end{array}$ & $\begin{array}{l}\text { (1) } 1.33(0.93-1.90), P=0.12 \\
\text { (2) } 1.10(0.91-1.31), P=0.32 \\
\text { (3) reference }\end{array}$ \\
\hline Incidence rate ${ }^{\dagger, \neq}$ & $\begin{array}{l}\text { (1) } 1.67 \\
\text { (2) } 1.96 \\
\text { (3) } 1.28\end{array}$ & $\begin{array}{l}\text { (3) } 1.4 \\
\text { (1), (2), (4) } 1.9-2.3\end{array}$ & $\begin{array}{l}\text { (1) } 3 \\
\text { (2) } 6 \\
\text { (3) } 4\end{array}$ \\
\hline All-cause death & & $\mathrm{P}=0.025^{\star}$ & \\
\hline $\begin{array}{l}\text { Adjusted HR } \\
(95 \% \mathrm{Cl}), \mathrm{P} \text { value }\end{array}$ & $\begin{array}{l}\text { (1) } 1.01(0.70-1.46), P=0.94 \\
\text { (2) } 1.01(0.84-1.23), P=0.88 \\
\text { (3) reference }\end{array}$ & $\begin{array}{l}\text { (1) } 1.10(0.85-1.42) \\
\text { (2) } 1.23(1.07-1.42) \\
\text { (3) reference } \\
\text { (4) } 0.99(0.76-1.30)\end{array}$ & NA \\
\hline Incidence rate ${ }^{\dagger}$ & $\begin{array}{l}\text { (1) } 4.62 \\
\text { (2) } 5.74 \\
\text { (3) } 3.21\end{array}$ & $\begin{array}{l}\text { (1) NA } \\
\text { (2) } 9.2 \\
\text { (3) } 4.5\end{array}$ & NA \\
\hline Hospitalization for $\mathrm{HP}$ & & & \\
\hline $\begin{array}{l}\text { Adjusted HR } \\
(95 \% \mathrm{Cl}), \mathrm{P} \text { value }\end{array}$ & $\begin{array}{l}\text { (1) } 1.28(0.86-1.92), P=0.22 \\
\text { (2) } 1.44(1.16-1.78), P=0.0008 \\
\text { (3) reference }\end{array}$ & NA & NA \\
\hline Incidence rate ${ }^{\dagger}$ & $\begin{array}{l}\text { (1) } 3.59 \\
\text { (2) } 4.41 \\
\text { (3) } 1.80\end{array}$ & NA & NA \\
\hline
\end{tabular}

Continuous variables are presented as the mean \pm standard deviation or medians (25th-75th interquartile ranges). Group (1) indicates the VAF group, Group (2) indicates the NVAF-VHD group, Group (3) indicates the no-VHD group. ${ }^{*} P$ value between the 3 groups and the reference group. †ncidence rates are presented as per 100 person-years in the studies of Doi et al ${ }^{6}$ and Thomas et al. ${ }^{7}$ \#ncidence rates are presented as \%/year estimated by Kaplan-Meier curves in the study of Bisson et al. ${ }^{8} \mathrm{AF}$, atrial fibrillation; AR, aortic regurgitation; AS, aortic stenosis; $\mathrm{BPV}$, bioprosthetic valve; $\mathrm{Cl}$, confidence interval; HF, heart failure; HR, hazard ratio; IQR, interquartile range; MR, mitral regurgitation; MS, mitral stenosis; MV, mechanical valve; NA, not applicable; NOAC, non-vitamin K antagonist oral anticoagulant; NVAF-VHD, non-valvular atrial fibrillation with valvular heart disease; SE, systemic embolism; TR, tricuspid regurgitation; VAF, valvular atrial fibrillation; VHD, valvular heart disease.

and the clinical outcomes in those VAF and NVAF-VHD patients.

In this issue of the Journal, Doi et al highlighted the patient characteristics and clinical outcomes in Japanese patients with AF and concomitant VHD by using the data from the Fushimi AF Registry, which is one well-known, large-scale Japanese AF registy. ${ }^{6}$ The recent findings on the clinical outcomes regarding patients with AF and VHD have only been reported in the Outcome Registry for Better Informed Treatment for Atrial Fibrillation (ORBIT-AF) ${ }^{7}$ and the report from the Regional University Hospital Centre (CHRU) of Tours in France by Bisson et al (Table). ${ }^{8}$ Patients in those two recent studies and those in the present studies, were similarly classified into 3 groups; that is, VAF, NVAF-VHD, and no-VHD groups; however, the ORBITAF study had an additional group including bioprosthetic valves, surgical repairs, and balloon valvuloplasty. In all the studies, the NVAF-VHD group was comparatively the oldest and had the highest $\mathrm{CHA}_{2} \mathrm{DS}_{2}$-VASc score, and the age in the VAF group was similar in the present and ORBIT-AF studies (74.3 and 74 years, respectively). Despite the less prevalent OAC use in the study by Doi et al, the stroke/SE and all-cause death rates in the VAF and NVAF-VHD groups were slightly lower than that in the other recent studies. A lower incidence of stroke/SE and all-cause death events in Japanese AF patients compared with that in Western populations, also has been reported in other large-scaled cohorts,,${ }^{\mathbf{9} 10}$ so it may be related to racialspecific factors, public health insurance, free access to medical facilities, and/or the lifestyle in Japan. Surprisingly, all the studies had an equivalent relative risk for stroke/SE in the VAF and NVAF-VHD groups as compared to the no-VHD group. In the ORBIT-AF study, the adjusted hazard ratio (HR) for all-cause death was significantly 
higher in the NVAF-VHD group than in the no-VHD group, while that difference was not observed in the present study. The other important finding of the present study was the outcome results for each type of NVAF-VHD group. In the present study, the relative risk for stroke/SE and all-cause death in the MS group was comparable to that in the no-VHD group (stroke/SE: adjusted HR 1.06, 95\% confidence interval [CI] 0.44-2.15, $\mathrm{P}=0.89$; all-cause death: HR $0.90,95 \%$ CI $0.51-1.47, \mathrm{P}=0.68$ ), as was observed with the other types of NVAF-VHD groups in comparison to the no-VHD group. Those results from the present and two recent studies differ from our understanding from the past studies that have reported a higher incidence of strokes and death in AF patients with VAF, including MS, than in those without VHD. It is possible that the development of the medical healthcare system and treatments including surgical intervention, the control and type of OACs, antihypertensive drugs, and/or lipid-lowing drugs in the recent period may have led to a better prognosis even in VAF patients. In contrast, the AS group in the present study had significantly higher adjusted HRs for cardiac death (HR 2.95, 95\% CI 1.54-5.66, $\mathrm{P}=0.001$ ) and heart failure (HF) hospitalizations (HR 1.78, 95\% CI 1.10 $2.88, \mathrm{P}=0.02$ ) than the no-VHD group as compared to that seen with the other types NVAF-VHD group. Similarly, the ORBIT-AF study also showed that the relative risk for all-cause death in the AS group as compared to the noVHD group was significantly higher (HR $1.40,95 \%$ CI 1.13-1.73, $\mathrm{P}=0.002$ ). That was reasonable because both AF and AS coexist with each other in older-aged patients with a high atherosclerosis risk, and the prognosis is poor with advancing severity of AS. In the super-aged society in Japan, those findings highlight the need for a careful follow up in AF patients with AS, and it should be noted that AS will have a stronger impact on the AF management.

Because this was an observational study, several limitations should be carefully interpreted. In the present study, NOAC usage tended to be lower than warfarin usage. In the clinical real-world setting, OAC therapy has changed in recent years, especially in patients with NVAF-VHD and no-VHD because the usage rate and variety of NOACs has increased.9,10 Thus, the clinical outcomes of AF with VHD may have been changing. In the study by Doi et al, the percentage of each severity level of VHD was unknown, and thus, the effect of each type of VHD on the clinical outcomes may have been underestimated. It would be difficult to distinguish whether the cause of cardiac death or HF hospitalization was due to AF itself or the severity of AS. Despite those unresolved issues, their data may provide informative insights into understanding the clinical outcomes of AF patients with a variety of VHDs. The findings of this study together with the recent studies suggest that it is the time we should update our understanding of the effect of VHD on the clinical outcomes in AF patients.

\section{Disclosures}

Y.O. has received research funding from Bayer Healthcare, DaiichiSankyo, Bristol-Meyers Squibb, Nippon Boehringer Ingelheim, Pfizer Japan, TORAY, and Boston Scientific Japan, and has accepted remuneration from Bayer Healthcare, Daiichi-Sankyo, and BristolMeyers Squibb.

\section{References}

1. Atarashi H, Inoue H, Okumura K, Yamashita T, Kumagai N, Origasa $\mathrm{H}$, et al. Present status of anticoagulation treatment in Japanese patients with atrial fibrillation: A report from the J-RHYTHM Registry. Circ J 2011; 75: 1328-1333.

2. Sherman D, Dyken M, Fisher M, Harrison M, Hart R. Cerebral embolism. Chest 1986; 89: 82S-98S.

3. Saito S, Tsukui H, Iwasa S, Umehara N, Tomioka H, Aomi S, et al. Bileaflet mechanical valve replacement: An assessment of outcomes with 30 years of follow-up. Interact Cardiovasc Thorac Surg 2016; 23: 599-607.

4. JCS Joint Working Group 2013. Guidelines for pharmacotherapy of atrial fibrillation (JCS 2013). https://www.jstage.jst.go.jp/ article/circj/78/8/78_CJ-66-0092/_pdf (accessed March 8, 2020).

5. Lip GYH, Collet JP, Caterina R, Fauchier L, Lane DA, Larsen TB, et al. Antithrombotic therapy in atrial fibrillation associated with valvular heart disease: A joint consensus document from the European Heart Rhythm Association (EHRA) and European Society of Cardiology Working Group on Thrombosis, endorsed by the ESC Working Group on Valvular Heart Disease, Cardiac Arrhythmia Society of Southern Africa (CASSA), Heart Rhythm Society (HRS), Asia Pacific Heart Rhythm Society (APHRS), South African Heart (SA Heart) Association and Sociedad Latinoamericana de Estimulación Cardíaca y Electrofisiología (SOLEACE). Europace 2017; 19: 1757-1758.

6. Doi K, Ogawa H, Ishigami K, Ikeda S, Aono Y, Hamatani Y, et $\mathrm{al}$; on behalf of the Fushimi AF Registry Investigators. Impact of valvular heart disease on mortality, thromboembolic and cardiac events in Japanese patients with atrial fibrillation: The Fushimi AF Registry. Circ J 2020; 84: 714-722.

7. Thomas K, Jackson L, Shrader P, Ansell J, Fonarow G, Gersh $\mathrm{B}$, et al. Prevalence, characteristics, and outcomes of valvular heart disease in patients with atrial fibrillation: Insights from the ORBIT-AF (Outcomes Registry for Better Informed Treatment for Atrial Fibrillation). J Am Heart Assoc 2017; 6: e006475.

8. Bisson A, Bodin A, Clementy N, Bernard A, Babuty D, Lip GYH, et al. Stroke, thromboembolism and bleeding in patients with atrial fibrillation according to the EHRA valvular heart disease classification. Int $J$ Cardiol 2018; 260: 93-98.

9. Okumura Y, Yokoyama K, Matsumoto N, Tachibana E, Kuronuma K, Oiwa K, et al. Three-year clinical outcomes associated with warfarin vs. direct oral anticoagulant use among Japanese patients with atrial fibrillation: Findings from the SAKURA AF Registry. Circ J 2018; 82: 2500-2509.

10. Kodani E, Atarashi H, Inoue H, Okumura K, Yamashita T, Origasa $\mathrm{H}$, et al. Beneficial effect of non-vitamin $\mathrm{K}$ antagonist oral anticoagulants in patients with nonvalvular atrial fibrillation: Results of the J-RHYTHM Registry 2. Circ J 2016; 80: 843-851. 